\title{
Aluminium Alloy Recrystallizing at Room Temperature
}

\author{
By Shinpei Maeda*
}

\begin{abstract}
In many cases, it is desirable to use soft aluminium which recrystallizes at room temperature. It would be convenient as well as economical, if such aluminum could be made easily and cheaply.

This research was successful in lowering the recrystallization temperature to below room temperature by the addition of a small amount of calcium to aluminium of commercial purity with high temperature soaking, and by heat treatment for a long time at low temperature. It was proved that the matrix of aluminium containing impurities could be almost completely purified by changing the impurities to a harmless state by the addition of calcium and by heat treatment. Consequently, the aluminium alloy obtained, besides having the property of softening at room temperature, has the properties excelling in sof tness, workability, electric conductivity and corrosion resistance peculiar to high purity aluminium.

Further, it was found that impurities such as magnesium, manganese and copper can be more readily changed to a harmless state by the addition of small amounts of tin, nickel, etc., together with calcium, and general properties of the elements, which can purify the matrix of aluminium by the addition of them, were studied.
\end{abstract}

(Received October 31, 1960)

\section{Introduction}

It is well known that commercial aluminium has to be heated to a temperature of about $300^{\circ} \mathrm{C}$ to soften it. However, it is desirable to have aluminium which recrystallizes at lower temperature depending on its uses. For instance, it would be convenient if cable sheaths could be made by such aluminium which recrystallizes at a temperature which would not impair the insulating materials of cables. It would be also convenient as well as economical if aluminium which softens at room temperature after working could be used as a material for foils and collapsible tubes, thereby resulting in the elimination of the annealing process.

The recrystallization temperature of aluminium is influenced by various factors, such as applied strain, rate of heating, heating temperature and time, and of these, the largest factor is the purity of the aluminium. Low-temperature recrystallizing aluminium, which has been used in the past, is aluminium of very high purity. It has been known that hard worked zone-refined aluminium having a purity of over $99.999 \%$ recrystallizes at room temperature, and also at a temperature of $-50^{\circ} \mathrm{C}$, and thet aluminium of such purity is practically non-work hardening at room temperature. (1) (4)

However, as zone-refined aluminium is a special material for commercial uses, aluminium containing small amounts of impurities have to be used for room temperature softening aluminium. But, it has been known that electrolytically refined four nine aluminium, which has a purity slightly lower than that

* The Nikko Copper Works, The Furukawa Electric Co., Ltd.

(1) A. W. Demmler; J. Metal Aug. (1956), 958.

(2) P. Albert and O. Dimitory: Compt. rend., 245 (1957), 681.

(3) F. Montriol: Compt. rend. 238 (1954), 815.

(4) G.Chaudron: Congres International de 1'Aluminium, Paris 1 (1954), 179

(5) D. Altenpohl: Z. Metallk., 49 (1958), 338. of zone-refined aluminium, will not recrystallize unless it is heated to a temperature of about $100^{\circ} \mathrm{C}$ to $250^{\circ} \mathrm{C}$.(5) ( 8 ) Moreover, it has been proved that the recrystallization temperature becomes higher when other elements are added to it. ${ }^{(9) \sim(14)}$ The reason is considered as follows. Since the lattice defects are locked by the elements forming a solid solution of aluminium, preventing the diffusion or annihilation of such defects, recovery and recrystallization may become very difficult. Thus, the recrystallization temperature usually becomes higher when other elements are added to aluminium.

Nevertheless, some attempts have been made in the past to lower the recrystallization temperature of aluminium by the addition of other elements. For aluminium of $99.9 \%$ purity, Anderson(15) succeeded in lowering the recrystallization temperature by about $100^{\circ} \mathrm{C}$ by the addition of $0.01 \%$ to $0.02 \%$ of beryllium, or by the addition of $0.2 \%$ to $0.4 \%$ of nickel, or by the addition of both. However, the mechanism has not been clarified, and such phenomenon has not been observed for aluminium of four nine purity. (15)

The alloys obtained by Anderson are very interesting, but it is necessary to anneal up to $200^{\circ} \mathrm{C}$ again for complete recrystallization, and thus, there will be little hope of putting the above alloys into practical uses.

(6) D. Altenpohl: Metall März, (1959), 181.

(7) N. Kawashima and Y. Nakamura: J.Japan Inst. Metals, 16 (1952), 73.

(8) J. Cablvet: Metallurgist, 10 (1935), 36;

(9) D. Altenpohl: Aluminium, 33 (1957), 5, 306.

(10) G.Masing, K.Lücke and P.Nölting: Z.Metallk.,47(1956), 64.

(11) E. Kratz: Aluminium Archiv. 6 (1937), 7.

(12) H. Chossat: Rev. Metallurgie 47 (1950), 3.

(13) N.Kawashima and Y.Nakamura: J. Japan Inst. Metals, 16 (1952), 26.

(14) J.C. Blade, J. W. H. Clare and H. J. Lamb: J. Inst. Metals $88(1960), 365$.

(15) W.A.Anderson: Japanese Patent 208, 505; T. I. McClinton, A. L. Hurst; U. S. Patent 2, 670, 309 . 
Yanagisawa and Matsuo(16) carried out research on the effects of the addition of calcium to four nine aluminium on the recrystallization temperature. According to them, annealing curves of $95 \%$ rolled specimens of alloys containing $0.48 \%$ to $0.71 \%$ of calcium after intermediate annealing, showed that complete recrystallization occurred by heating at $150^{\circ} \mathrm{C}$ for 1 hour. However, with aluminium containing over $2 \%$ of calcium, there was no lowering of the recrystallization temperature. The reason for the occurrence of such phenomena was not clarified.

Further research was carried out with regard to the effects of calcium, but unsatisfactory results were reported, namely, with regard to ingot specimens of aluminium of $99.3 \%$ to $99.99 \%$ purity to which $0.07 \%$ to $2 \%$ of calcium are added and then $98 \%$ rolled, the results obtained showed that the recrystallization temperatures of all of these specimens were hardly changed by the addition of calcium. (17) And it was clarified also that there was a slight rise in the recrystallization temperature with increasing calcium contents of $90 \%$ rolled specimens of four nine purity aluminium containing less than $0.072 \%$ of calcium.(18) Besides the above studies, further research has been carried out on Al-Ca alloys and so far, $(19)(20)$ there have been no reports on the lowering of the recrystallization temperature.

\section{Methods for the Lowering of Recrystal- lization Temperature of Al-Ca Alloys}

In spite of many negative facts, the report of Yanagisawa and Matsuo(16) includes a noteworthey fact to be further studied, since the effects of nickel and beryllium are already known, ${ }^{(15)}$ and further, it has been known that calcium combines with silicon contained in aluminium, and changes silicon into insoluble $\mathrm{CaSi}_{2}$. 19 (21)

Then, at first the author studied the effects of hydrogen which combines in large quantity with calcium, ${ }^{(22)}$ but it became clear that there was no relationship between hydrogen and the phenomenon of the lowering of recrystallization temperature of aluminium. (23) Secondly, experiments in the present paper were carried out with regard to precipitation heat treatments of intermetallic compounds of calcium-impurities and calcium itself, which have the possibility to form super-saturated solid solution in aluminium at low temperature.

High purity aluminium, and aluminium of commercial purity to each of which calcium was added,

(16) M. Yanagisawa and S. Matsuo: Light Metals (Japan) No. 16 (1955), 69.

(17) T.Ushioda, O.Yoshimura and S. Mashiyama: Light Metals (Japan) No. 19 (1956), 34.

(18) Y. Nakamura and M. Nishizaka: Light Metals (Japan) No. 20 (1956), 58.

(19) W. Rosenhain, J. D. Grogan: British Patent No. 211, 027; J. D. Grogan: J. Inst. Metals 37 (1927), 77.

(20) D.Edward and C.S.Taylor: Am. Electrochem. Soc. Advance Copy Oct (1926), 32; Met. Ind. 29 (1926), 359.

(21) E. Doan: Z. Metallk., 18 (1926), 350.

(22) Johnson, Stubbs, Sidewell and Pechukas: J. Am. Chem. Soc., 61 (1939), 318.

(23) S. Maeda: Furukawa Elec. Rev. No. 22 (1960), 84. were used as specimens for the present experiments. Table 1 shows the chemical analysis of the specimens.

The surfaces of ingots of specimens No. 2 and No. 5 were scalped, after which sheets of $2 \mathrm{~mm}$ thickness obtained by $85.7 \%$ cold rolling were subjected to intermediate annealing at $200^{\circ} \mathrm{C}$ to $550^{\circ} \mathrm{C}$ for 1 hour.

Table 1 Chemical analysis of spcimens.

\begin{tabular}{|c|c|c|}
\hline Specimen No. & Purity of $\mathrm{Al} \%$ & $\mathrm{Ca}^{*}$ wt $\%$ \\
\hline $\begin{array}{l}1 \\
2 \\
3\end{array}$ & 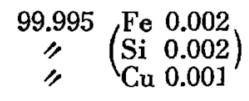 & $\begin{array}{l}\overline{0.51} \\
0.93\end{array}$ \\
\hline $\begin{array}{l}4 \\
5\end{array}$ & 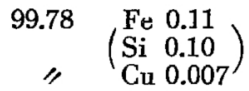 & - \\
\hline
\end{tabular}

* $99.5 \% \mathrm{Ca}(\mathrm{Mg} \mathrm{0.45,} \mathrm{Al} 0.018, \mathrm{~N} 0.020)$.

The sheets were then cold rolled to a thickness of $0.1 \mathrm{~mm}$, and the hardness change of these foils, after half an hour heating, were measured. The effects of addition of calcium, and intermediate annealing can be observed by comparing the recrystallization temperatures of the above foils with those of the foils of No. 1 , No. 2, No. 4 , and No. 5 which were not subjected to intermediate annealing at all, i.e., cold rolled directly from ingots to a thickness of $0.1 \mathrm{~mm}$.

As shown in Fig. 1 and Fig. 2, it was clarified that calcium has the outstanding characteristic of lowering the recrystallization temperature of aluminium very remarkably.

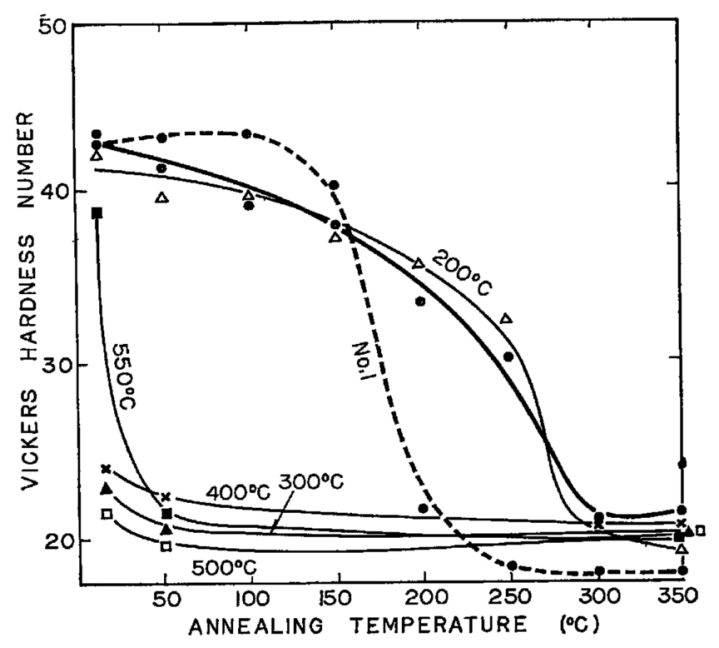

Fig. 1 Effect of intermediate annealing temperature indicated, on the annealing curves of specimens No. 2 and No. 1 (broken line).

Thick lines show specimens not intermediately annealed.

However, mere addition of calcium raises the recrystallization temperature. Theus, calcium itself is considered to have the effect of acting as a kind of impurity, and heat treatment is absolutely necessary for lowering the recrystallization temperature of Al-Ca alloys.

For specimen No. 2 of high purity aluminium, heat treatment temperatures between $300^{\circ} \mathrm{C}$ and $550^{\circ} \mathrm{C}$ are effective. Above all, a temperature of about $500^{\circ} \mathrm{C}$ was the most effective temperature, which 
enabled the specimen to recrystallize almost completely at room temperature by heating only for 1 minute, but when the amount of the elements of impurities was increased the effect of calcium was hindered, and the range of effective heating temperature became small, and was limited to about $300^{\circ} \mathrm{C}$. Furthermore,

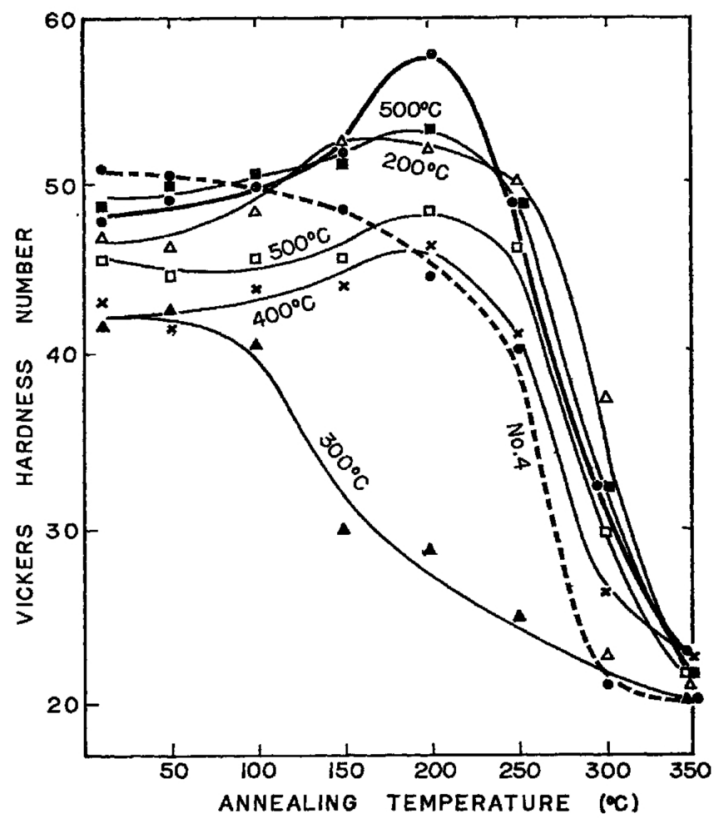

Fig. 2 Effect of intermediate annealing temperature indicated on the annealing curves of specimens No. 5 and No. 4 (broken line).

Thick lines show specimens not intermediately annealed.

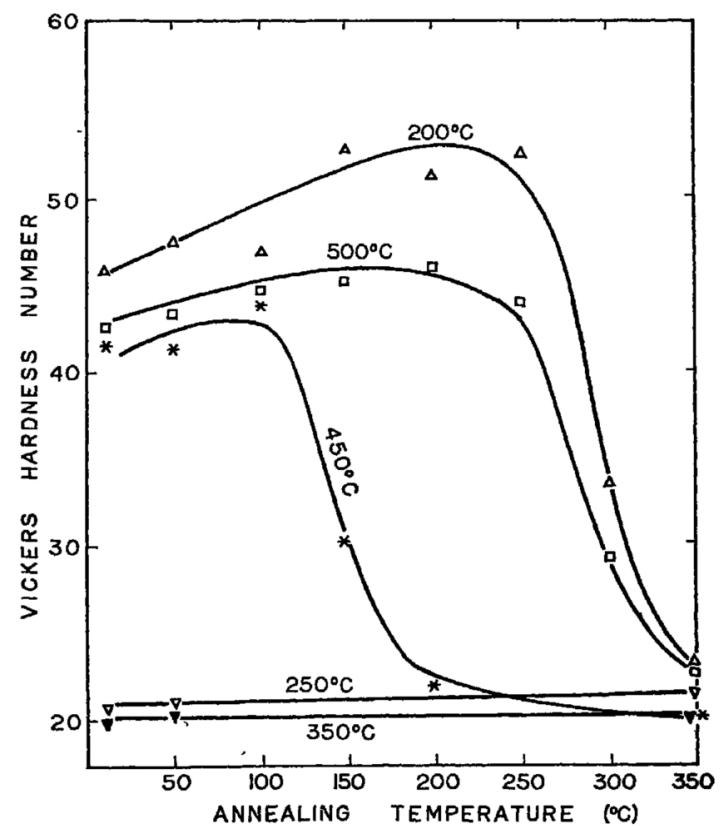

Fig. 3 Effect of prolonged intermediate annealing at the temperature indicated, on the recrystallization temperatures of specimen No. 5 .

in the specimens which were not subjected to heat treatment at all, or in specimens which were subjected to improper intermediate annealing, the phenomenon of hardening due to low temperature annealing was observed at about $200^{\circ} \mathrm{C}$.

Fig. 3 is the results obtained in the case of specimen No. 5 subjected to intermediate annealing for 10 hours instead of 1 hour. When heating was done at a proper temperature, the effects became greater with increase in the time of heat treatment.

Further, large effect can be obtained in the specimens not only by heating at a constant temperature, but also by slow cooling within the proper range of temperature.

From the above results, it can be considered that the desirable state of Al-Ca alloy can only be obtained by heating at a proper temperature for a long time. And it is supposed that calcium itself does not have solubility in aluminium below about $500^{\circ} \mathrm{C}$.

Further, it was verified that the degree of cold work before heat treatment also has a remarkably large effect on the lowering of the recrystallization temperature of Al-Ca alloys.

The surfaces of each of the four ingots of specimen No. 5 were scalped down to proper thickness after which they were rolled to a thickness of $2 \mathrm{~mm}$, each degree of working was regulated exactly at $88 \%$, $75 \%, 50 \%$ and $0 \%$ respectively. All of the specimens of $2 \mathrm{~mm}$ thickness were heated at $350^{\circ} \mathrm{C}$ for 10 hours after which they were rolled down to $0.1 \mathrm{~mm}$, and their recrystallization temperatures by half an hour heating were determined. Fig. 4 shows such effects.

Soaking heat treatment of the ingots also has a very desirable "effect. Fig. 5 shows the annealing curves of foils of $0.1 \mathrm{~mm}$ thickness which were obtained by using the soaking treatment on ingots of No. 3 and No. 5 specimens at $350^{\circ} \mathrm{C}$ to $550^{\circ} \mathrm{C}$ for 20 hours and

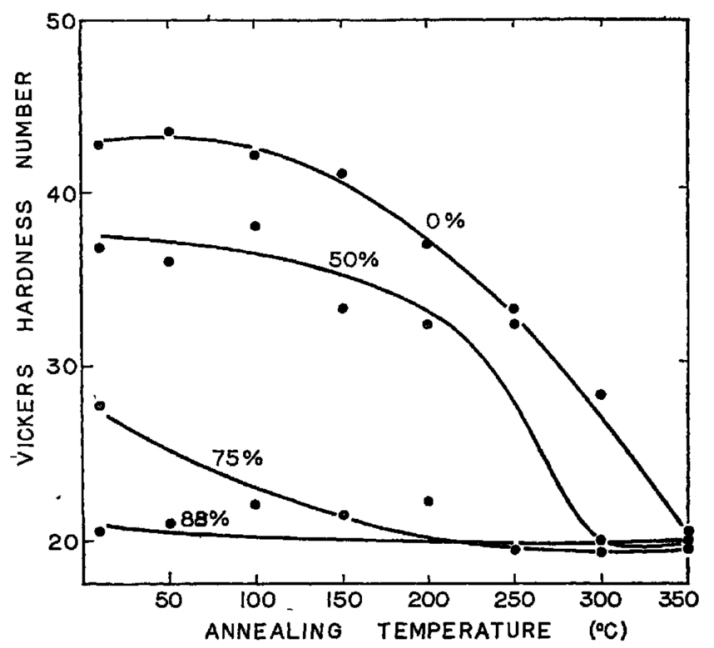

Fig. 4 Effect of reduction by rolling before intermediate annealing on the annealing curves of specimen No.5.

rolled down to a thickness of $2 \mathrm{~mm}$ after which they were subjected to intermediate annealing at $350^{\circ} \mathrm{C}$ for 1 minute and then rolled down to $0.1 \mathrm{~mm}$. The effects of ingot soaking can thus be clarified. For specimen No. 3 , a temperature of $500^{\circ} \mathrm{C}$ which was the same as in the case of intermediate annealing was the most effective temperature, and in this case, softening at room temperature occurs even when intermediate annealing was omitted. However, for specimen No. 5 , the temperature was entirely different from that of the case of intermediate annealing and the soaking temperature of around $500^{\circ} \mathrm{C}$ likewise showed the 
maximum effect in the same way as in the case of specimen No. 3 , and the effects become greater with increase in the soaking time. However, as can be clearly seen by comparing Fig. 5 with Figs. 2 and 3, the effect of such soaking treatment is considerably smaller than that of precipitation treatment.

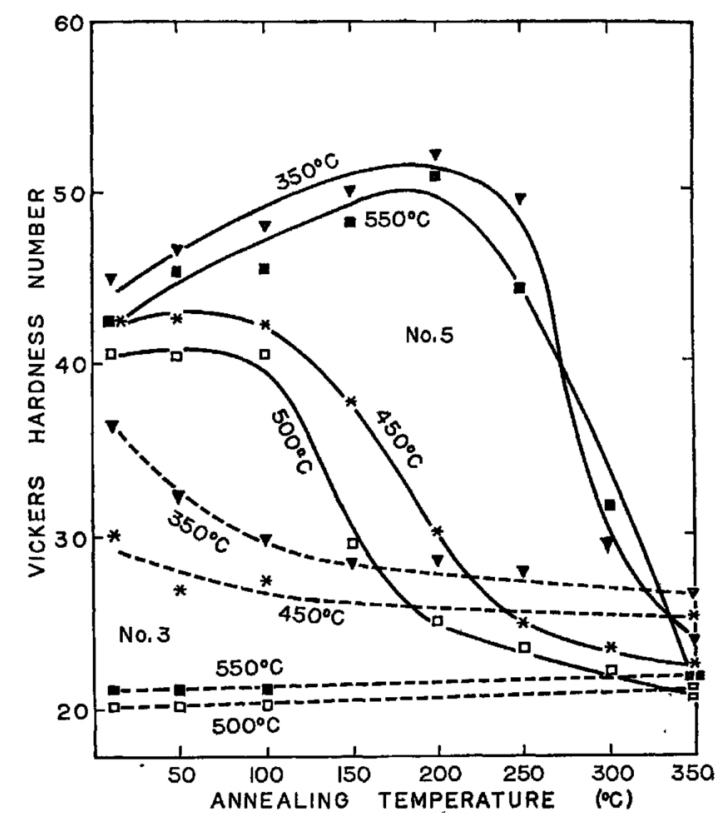

Fig. 5 Effect of ingot soaking temperature indicated on annealing curves of specimen No. 3. (broken line) and No. 5 (full line).

In summarizing the above, in order to lower the recrystallization temperature of Al-Ca alloys, it was necessary to carry out the soaking heat treatment of the ingots at around $500^{\circ} \mathrm{C}$ for a long time, and subject the alloys to as much strain as possible by subsequent cold working after which high purity Al-Ca alloys should be subjected to heat treatment at about $500^{\circ} \mathrm{C}$, and low purity Al-Ca alloys should be subjected to heat treatment at between 250 and $350^{\circ} \mathrm{C}$ for a long time, and finally, should be subjected to a high degree of working.

Generally, with increase in the amount of added calcium lowering of recrystallization temperatures could be achieved more readily, and if heat treatment was properly done, addition of less than $0.5 \%$ of calcium to aluminium of the purity of $99.78 \%$ and over would serve the purpose, and so, it could not be expected to have any more effect even if the amount of calcium added was more than the above $0.5 \%$. (?3)

\section{Interaction Between Various Kinds of Elements of Impurities and Calcium}

In the previous section, it was proved that the recrystallization temperature of high purity aluminium could be lowered rather readily, but this lowering became more difficult with the increase in the amount of impurities in aluminium. Determination of the recrystallization temperatures of high purity aluminium containing calcium and any of the various kinds of impurity elements which have a large possibility of being found in ordinary commercial aluminium were carried out. The following process was chosen as the method of working the specimens.

Ingots $14 \mathrm{~mm}$ thick $\left(500^{\circ} \mathrm{C} \times 20 \mathrm{hrs}\right)$, hot rolled 6 $\mathrm{mm}$, cold rolled $2 \mathrm{~mm}\left(350^{\circ} \mathrm{C} \times 10 \mathrm{hrs}\right.$. furnace cooled $300^{\circ} \mathrm{C} \times 10 \mathrm{hrs}$. furnace cooled $250^{\circ} \mathrm{C} \times 10$ hrs. air cooled $)$ cold rolled $0.1 \mathrm{~mm} \quad\left(\mathrm{~T}^{\circ} \mathrm{C} \times 1 / 2\right.$ hr).

Table 2 Influence of some impurities on the recrystallization temperature of $\mathrm{Al}-\mathrm{Ca}$ alloys.

\begin{tabular}{|c|c|c|c|}
\hline $\begin{array}{l}\text { Specimen } \\
\text { No. }\end{array}$ & $\begin{array}{l}-\mathrm{Ca} \\
\text { wt } \%\end{array}$ & $\begin{array}{l}\text { Impurity } \\
\text { added wt } \%\end{array}$ & $\begin{array}{c}\text { Recrystallization } \\
\text { temperature }{ }^{\circ} \mathrm{C}\end{array}$ \\
\hline $\begin{array}{l}6 \\
7\end{array}$ & $\overline{0.044}$ & - & $\begin{array}{c}175 \\
\text { room temperature }\end{array}$ \\
\hline $\begin{array}{l}8 \\
9\end{array}$ & $\overline{0.06}$ & 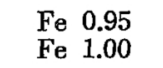 & $\begin{array}{c}250 \\
\text { room temperature }\end{array}$ \\
\hline $\begin{array}{l}10 \\
11 \\
12 \\
13 \\
14\end{array}$ & $\begin{array}{l}\overline{0.36} \\
0.37 \\
0.66 \\
1.86\end{array}$ & $\begin{array}{ll}\text { Si } & 0.07 \\
\text { Si } & 0.40 \\
\text { Si } & 0.55 \\
\text { Si } & 1.14 \\
\text { Si } & 1.02\end{array}$ & $\begin{array}{c}300 \\
\text { room temperature } \\
150 \\
250 \\
\text { room temperature }\end{array}$ \\
\hline $\begin{array}{l}15 \\
16 \\
17 \\
18 \\
19\end{array}$ & $\begin{array}{l}-\overline{1.89} \\
1.07 \\
2.36 \\
1.90\end{array}$ & $\begin{array}{ll}\mathrm{Cu} & 0.29 \\
\mathrm{Cu} & 0.21 \\
\mathrm{Cu} & 0.23 \\
\mathrm{Cu} & 0.34 \\
\mathrm{Cu} & 0.41\end{array}$ & $\begin{array}{c}275 \\
\text { room temperature } \\
300 \\
75 \\
250\end{array}$ \\
\hline $\begin{array}{l}20 \\
21 \\
22 \\
23 \\
24\end{array}$ & $\begin{array}{l}-\overline{23} \\
1.48 \\
2.35 \\
1.02\end{array}$ & $\begin{array}{l}\mathrm{Mg} 0.047 \\
\mathrm{Mg} 0.012 \\
\mathrm{Mg} 0.014 \\
\mathrm{Mg} 0.017 \\
\mathrm{Mg} 0.042\end{array}$ & $\begin{array}{c}250 \\
\text { room temperature } \\
100 \\
300 \\
300\end{array}$ \\
\hline $\begin{array}{l}25 \\
26 \\
27\end{array}$ & $\begin{array}{l}-\overline{18} \\
1.82\end{array}$ & $\begin{array}{l}\text { Mn0.080 } \\
\text { Mn0.024 } \\
\text { Mn } 0.033\end{array}$ & $\begin{array}{c}300 \\
\text { room temperature } \\
300\end{array}$ \\
\hline $\begin{array}{l}28 \\
29 \\
30\end{array}$ & $\begin{array}{l}0.21 \\
0.20 \\
2.40\end{array}$ & $\begin{array}{l}\text { Zn } 0.38 \\
\text { Zn } 0.57 \\
\text { Zn } 4.01\end{array}$ & $\begin{array}{c}\text { room temperature } \\
100 \\
\text { room temperature }\end{array}$ \\
\hline
\end{tabular}

Table 2 shows the chemical analysis of the specimens and the temperatures at which recrystallization was completed when the specimens were subjected to work according to the above method. The calcium used and high purity aluminium are the same as shown in Table 1. From the above results, it became clear that, at first, the above process of working was remarkably effective in lowering the recrystallization temperatur. It may be worthy to take note of the fact that four nine aluminium recrystallizes readily at room temperature with only a minute amount of $0.044 \%$ calcium as shown in No. 7 . Therefore, it can be safely concluded that the element added to the specimen is harmful when the specimen with a calcium content of over $0.044 \%$ does not recrystallize at room temperature, due to the fact that the effect becomes greater with increasing amounts of calcium.

The way in which each of the impurity elements becomes harmless may be interpreted as follows. It can be said that no matter what amount of iron is present in aluminium, iron is changed to a harmless state by a very small amount of calcium. Silicon and zinc can be changed to a harmless state by the addition of calcium in the amount of over a certain ratio of calcium to silicon and zinc. However, magnesium and manganese are harmful even in very 
small amounts, and if the amounts of such elements are over certain amounts, they no longer can be changed to harmless states even by the addition of large amounts of calcium. When increasing amounts of calcium are added to aluminium, there will be increase in the readiness of copper to change to a harmless state, at least when copper is present up to about $0.3 \%$. Besides the above, it was proved that nickel will be changed to a harmless state in the same way as that of iron, and chromium will be changed in the same way as those of magnesium and manganese and that their allowable amounts were about $0.05 \%$ and $0.09 \%$ respectively.

The recrystallization temperatures of $\mathrm{Al}-\mathrm{Mg}$ alloys became higher by the addition of calcium as shown in Fig. 6. The same phenomenon was observed in Al-Mn alloys.

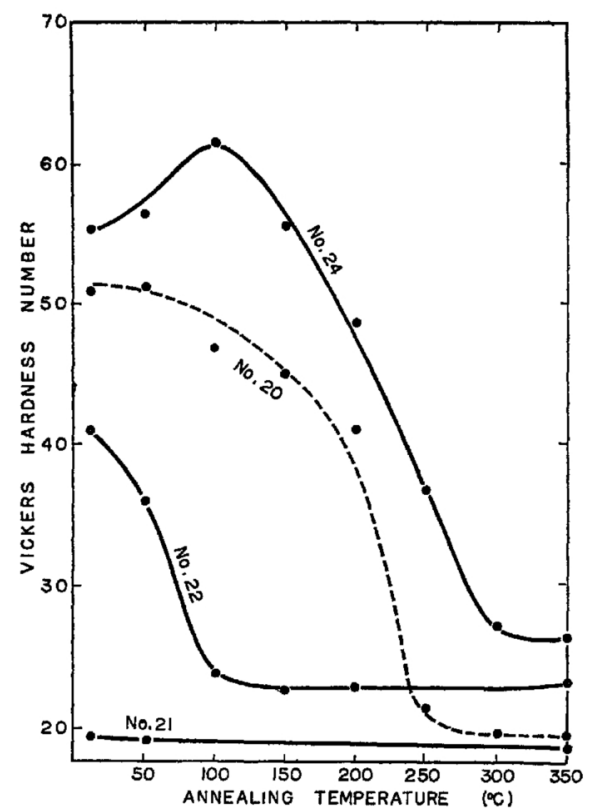

Fig. 6 Annealing curves of Al-Mg (broken line) and Al-Ca-Mg alloys.

Furthermore, Al-Mg alloys did not show any hardening by annealing at low temperatures, and in spite of the fact that $\mathrm{Al}-\mathrm{Ca}$ alloys also did not harden by annealing at low temperatures, ${ }^{(23)} \mathrm{Al}-\mathrm{Ca}-\mathrm{Mg}$ alloys showed considerable hardening. $\mathrm{Al}-\mathrm{Ca}-\mathrm{Mn}$ alloys showed an entirely similar phenomenon at about 150 to $200^{\circ} \mathrm{C}$, and such hardening was increased with the increase in the amount of working in both $\mathrm{Al}-\mathrm{Ca}-\mathrm{Mg}$ and $\mathrm{Al}-\mathrm{Ca}-\mathrm{Mn}$ alloys. ${ }^{(23)}$ However, very little hardening wás observed in the cases of $\mathrm{Al}-\mathrm{Ca}-\mathrm{Cu}$ alloys.

From the results obtained above, the degree of raising the recrystallization temperatures of $\mathrm{Al}-\mathrm{Ca}$ alloys due to impurity elements, i. e., the difficulty of changing these elements to a harmless state by calcium; are tabulated as shown in Table 3.

\section{Mechanism of the Lowering of the Recrystallization Temperature of Al-Ca Alloys}

Invẹstigations were carried out with regard to the sighificance of the three treatments required for lowering the recrystallization temperature of aluminium, namely, the addition of calcium, heat treatment and working, as well as the mech.anism of changing each of the various impurity elements of Table 3 to a harmless state by the above treatments.

Table 3 Classification and characteristics of the elements of impurities.

\begin{tabular}{|c|c|c|c|c|}
\hline Group & $\begin{array}{l}\text { Elements } \\
\text { in the } \\
\text { group }\end{array}$ & $\begin{array}{c}\text { Difficulty in } \\
\text { changing into } \\
\text { harmless state } \\
\text { by Ca }\end{array}$ & $\begin{array}{c}\text { Allowable } \\
\text { amount, wt } \% \\
\text { (approximate } \\
\text { value) }\end{array}$ & $\begin{array}{l}\text { Amount of } \mathrm{Ca} \\
\text { required }\end{array}$ \\
\hline I & $\begin{array}{l}\mathrm{Mg} \\
\mathrm{Mn} \\
\mathrm{Cr} \\
\mathrm{Ti}\end{array}$ & $\begin{array}{l}\text { Very } \\
\text { difficult }\end{array}$ & $\begin{array}{l}<0.015 \\
<0.03 \\
<0.05 \\
<0.09\end{array}$ & Small amount \\
\hline II & $\mathrm{Cu}$ & Difficult & $\begin{array}{l}\text { Probably no } \\
\text { limit }\end{array}$ & $\begin{array}{l}\mathrm{Ca} / \mathrm{Cu}>\mathrm{about} \\
7 \text {, at least }\end{array}$ \\
\hline III & $\begin{array}{l}\mathrm{Si} \\
\mathrm{Zn}\end{array}$ & Easy & No limit & $\begin{array}{r}\mathrm{Ca} / \mathrm{Si} \geq \mathrm{about} \\
0.7 \\
\mathrm{Ca} / \mathrm{Zn} \geq \mathrm{about} \\
0.5\end{array}$ \\
\hline IV & $\begin{array}{l}\mathrm{Fe} \\
\mathrm{Ni}\end{array}$ & $\begin{array}{l}\text { Almost } \\
\text { harmless }\end{array}$ & No limit & $\begin{array}{l}\text { Very small } \\
\text { amount }\end{array}$ \\
\hline
\end{tabular}

\section{Addition of calcium}

i. The main significance of the addition of calcium to aluminium is in the changing of the impurity elements to the state of insoluble intermetallic compounds in aluminium.

The ratio of $\mathrm{Ca} / \mathrm{Si}=0.7$ is just the composition of CaSi_. Elements of group 3 of Table 3 are considered to belong to this type.

It may be possible also that calcium dissolves harmful elements such as copper resulting in an intermetallic compound $\mathrm{Al}_{4} \mathrm{Ca}(\mathrm{Cu})$ which does not have any solubility in aluminium. In fact, the copper concentration of the ingot specimen No. 16 , estimated by the EPMA test, was about $0.5 \%$ at the grain boundaries and was not detected clearly in the interior parts of the grains.

ii. Even when intermetallic compounds have solubility down to room temperature, as long as that amount is minute, the process changing these impurities to harmless states is still possible. In otber words, when the impurities dissolve in aluminium in the form of compounds of calcium and impurities, since the interaction between such atoms are atrong, it may be considered that comparing the above with the case of the atoms of impurities alone forming solid solution, the interaction of such atoms with lattice defects will be remarkably weakened and the effect to raise the recrystallization temperature will almost disappear. However, the influence of the soluble compounds will appear if the amount of im turities exceeds the allowable amount, and the amount of such compounds becomes considerably large.

From the consideration of the facts that the recrystallization temperatures are raised by the addition of calcium to aluminium which contains more than the allowable amounts of magnesium or manganese, etc., and that they show hardening by low temperature annealing, it may be considered that magnesium and 
manganese combine with calcium. It may also be a fact that the hardening which occurs at 100 to $200^{\circ} \mathrm{C}$ is the phenomenon observed in precipitating super-saturated elements. The hardening occurs more apparently when the heat treatment is improper, when the degree of final work is large, and when the amount of impurities and calcium are large.

Elements in group I of Table 3 are considered to belong to this type.

It may be allowed to apply almost similar mechanism to aluminium containing minute amounts of impurities which do not produce an intermetallic compound with calcium. It is known that iron and nickel do not combine with calcium and that they have no solubility in aluminium at low temperature, (25) but, even if they were in super-saturated solution in minute amount, they would be changed to a harmless state in the same way. Consequently, in these cases, the process can be achieved by adding only a very small amount of calcium.

Minute amounts of other elements may be still present in a solid solution of $\mathrm{Al}-\mathrm{Ca}$ alloys which are strongly work-hardened at room temperature, even though they recrystallize at room temperature. So, it may be permissible to adopt the above mentioned mechanism as a mechanism of lowering the recrystallization temperature.

\section{Heat treatments}

i. Minute amount of impurities present in highpurity $\mathrm{Al}-\mathrm{Ca}$ alloys such as those of specimen No. 2, may be changed to a harmless state almost completely by the mechanism mentioned in (1)-ii, but as calcium itself acts $\approx \mathrm{s}$ a kind of impurity atoms, a rise in the recrystallzation temperature is observed when precipitation treatment is insufficient. (See Fig. 1)

With regard to the $\mathrm{Al}-\mathrm{Ca}$ equilibrium phase diagram, there are several reports(21)(24) $\sim(27)$ but they do not necessarily agree with each other. For instance, Donski(24) mentioned that a solid solution does not exist while other authors indicated that a solid solution exists down to a low temperature, and another author gave an extreme opinion that calcium of about $0.7 \%$ by weight forms a solid solution at room temperature.

However, from the experimental results obtained using high purity Al-Ca alloys such as No. 2, it may be concluded that calcium does not have the solubility in the temperature range of below $500^{\circ} \mathrm{C}$, at least that calcium does not dissolve so much amout as it raises the recrystallizatin temperature to above room temperature.

Precipitation treatment of specimen No. 5 containing large amount of impurities is the most effective when it was carried out at about $350^{\circ} \mathrm{C}$ to $300^{\circ} \mathrm{C}$. The reason may be due to the fact that the compounds

(24) L. Donski: Z. anorg. allg. Chem., 57 (1908), 21.

(25) . M. Hansen: Constitution of Binary Metals, (1958),

(26) K. Matsuyama: Kinzoku no Kenkyu, 2 (1925), 1004; Sci. Rept. Tohoku Univ. 17 (1928), 783.

(27) A. S. M. Metals Handbook, (1948). formed by the combination of the impurities and calcium, have no solubility in alminium below about $350^{\circ} \mathrm{C}$ to $300^{\circ} \mathrm{C}$.

ii. Soaking treatment is rather effective, but its effect is inferior to that of precipitation treatment. This mechanism is not clear. However, it can be considered that the first reason is probably that some kind of effective reaction which can not be done completely in rapid solidification proceeds during heating at high temperature for a long time. For instance, with regard to copper the phase diagram is not clear (25)(28) but it may be assumed that considering the results of Tables 2 and 3, copper changes to a harmless state by dissolving into calcium more completely. A similiar mechanism might be applied to other elements.

Next, high temperature soaking treatment aggregates the fine $\mathrm{Al}_{4} \mathrm{Ca}$ compounds into large particles, and as a result of such aggregation, strain due to working will be further increased when the same working is carried out. Then it may be considered that this strain has an effective action upon the precipitation of the impurities. A similar effect will be obtained by adding large amounts of calcium, but in actual cases, even if considerably larger amounts of calcium are added, no more effect on the lowering of the recrystallization temperature would result. In other words, it may be concluded that the presence of such large particles is of secondary meaning only.

\section{Hard working}

As is well known, hard working prior to intermediate annealing or of finish is a very effective method of accelerating precipitation or recrystallization by reducing the activation energy of such processes, especially for super high purity aluminium or properly heat treated $\mathrm{Al}-\mathrm{Ca}$ alloys.

\section{Confirming experiments}

The results of the experiments carried out to confirm the above conclusions are described as follows.

i. The measurements of changes of the lattice constants of Al-Ca alloys subjected to various kinds of heat treatment were done but very little differences were observed. It was difficult to detect such minute amount of solubility as differences in the lattice constant.

ii. Specimens of $2 \mathrm{~mm}$ thickness which were heat treated to precipitate perfectly and confirmed to have the characteristic of room temperature recrystallization after cold work of $95 \%$ reduction, were re-heated to a higher temperature and the degree of impairment of that characteristic were measured. In other words, attempts were made to investigate the lowest temperature above which the $\alpha$ solid solution could exist by the fact that the aluminium matrix, once purified by heat treatment at $300^{\circ} \mathrm{C}$ for 20 hours, will again dissolve other elements when re-heated to a higher temperature for 20 hours resulting in raising the

(28) N. Baar: Z. anorg. allg. Chem., 70 (1911), 37. 
recrystallization temperature. The results obtained are as shown in Table 4.

From these results it was proved that, contrary to equilibrium phase diagrams of the past, calcium have no solid solubility in aluminium below $500^{\circ} \mathrm{C}$, and which contain about $1 \%$ calcium and were heat treated at $300^{\circ} \mathrm{C}$ showed the values of about $2.80,2.89$, and $3.01 \mu \Omega-\mathrm{cm}$ respectively. These results can be considered to indicate that manganese and chromium are in a solid solution in aluminium even after calcium

Table 4 Relationship between impurity elements and temperatures at which a solid solution forms again.

\begin{tabular}{|c|c|c|c|c|c|c|c|c|c|c|c|c|c|}
\hline \multirow{3}{*}{$\begin{array}{l}\text { Specimen } \\
\text { No. }\end{array}$} & \multirow{3}{*}{$\begin{array}{c}\text { Impurity } \\
\text { added } \\
\text { wt } \%\end{array}$} & \multirow{3}{*}{$\begin{array}{c}\mathrm{Ca} \\
\text { wt } \%\end{array}$} & \multicolumn{11}{|c|}{ Degree of softening of $0.1 \mathrm{~mm}$ foil, $95 \%$ rolled, at room temperature } \\
\hline & & & \multirow{2}{*}{\begin{tabular}{|c|} 
Original \\
sheet, heat \\
treated at \\
$300^{\circ} \mathrm{C}$
\end{tabular}} & \multicolumn{10}{|c|}{ Reheating temperature $\left({ }^{\circ} \mathrm{C}\right)$ of original sheet } \\
\hline & & & & 325 & 350 & 375 & 400 & 425 & 450 & 475 & 500 & 525 & 550 \\
\hline 2 & - & 0.51 & O & 0 & 0 & 0 & O & O & 0 & 0 & 0 & (B) & \\
\hline 31 & Fe 1.01 & 0.37 & 0 & 0 & 0 & 0 & 0 & 0 & 0 & (1) & & & \\
\hline $\begin{array}{l}11 \\
28\end{array}$ & $\begin{array}{ll}\text { Si } & 0.40 \\
\text { Zn } & 0.38\end{array}$ & $\begin{array}{l}0.36 \\
0.21\end{array}$ & 0 & $\bigcirc$ & & & 向 & 曲 & & & & & \\
\hline $\begin{array}{l}16 \\
32 \\
22 \\
33\end{array}$ & $\begin{array}{l}\mathrm{Cu} 0.21 \\
\mathrm{Mn} 0.024 \\
\mathrm{Mg} 0.014 \\
\mathrm{Cr} 0.041\end{array}$ & $\begin{array}{l}1.89 \\
1.01 \\
1.48 \\
0.98\end{array}$ & $\stackrel{\bigcirc}{\oplus}$ & $\stackrel{0}{(1)}$ & & (1) & $\stackrel{0}{0}$ & 電 & & & & & \\
\hline 5 & $99.78 \% \mathrm{Al}$ & 0.50 & 0 & 0 & 0 & 0 & (1) & & & & & & \\
\hline
\end{tabular}

Degree of sof tening after 24 hours at room temperature: Fully recrystallized

that $\mathrm{CaSi}_{2}$ have the ability to form a solid solution above $400^{\circ} \mathrm{C}$, i. e., the $\mathrm{Al}-\mathrm{Ca}$ and $\mathrm{Al}-\mathrm{CaSi}_{2}$ phase diagram which were believed to be true in the past, were perhaps due to the low purity of materials used or to improper heat treatment, and so a correction may be necessary.

Alloy No. 31 containing iron loses its softening characteristic at room temperature when heated above $475^{\circ} \mathrm{C}$. It is due to the possibility of increasing minute amounts of silicon, copper, etc., contained in high-purity aluminium, all of which form a solid solution rather than the increase in the amount of iron forming a solid soution with a rise of temperature. The same process may occur in aluminium if it contains such impurities as $(\mathrm{Ca}-\mathrm{Mn})$ or (Ca-Mg) which are considered to have solubility in aluminium. Namely, specimen No. 33 containing a far smaller amount of chromium than the allowable amount indicated in Table 3 , shows good recrystallization characteristics even on reheating up to $500^{\circ} \mathrm{C}$, but in the case of specimens No. 22 and No. 32 to which the amounts close to the allowable amounts are added, it can be considered that by reheating at temperatures above $425^{\circ} \mathrm{C}$, further formation of a solid solution of minute amounts of $(\mathrm{Ca}-\mathrm{Si})$ and $(\mathrm{Ca}-\mathrm{Cn})$ will result in the rise of the recrystallzation temperature.

iii. In order to detect small differences of solubility by electric resistance, wires were made by almost the same process from the same specimens, shown in Table 4, and their electric resistance were measured. The measurements were made on wires $1 \mathrm{~mm}$ diameter after heat treatments at $300^{\circ} \mathrm{C}$ to $580^{\circ} \mathrm{C}$ for 20 hours, without reheating or further working. The results are shown in Fig. 7. These resuts compared very well with those of Table 4.

Further, specimen No. 3 , No. 32 and No. 33 each of

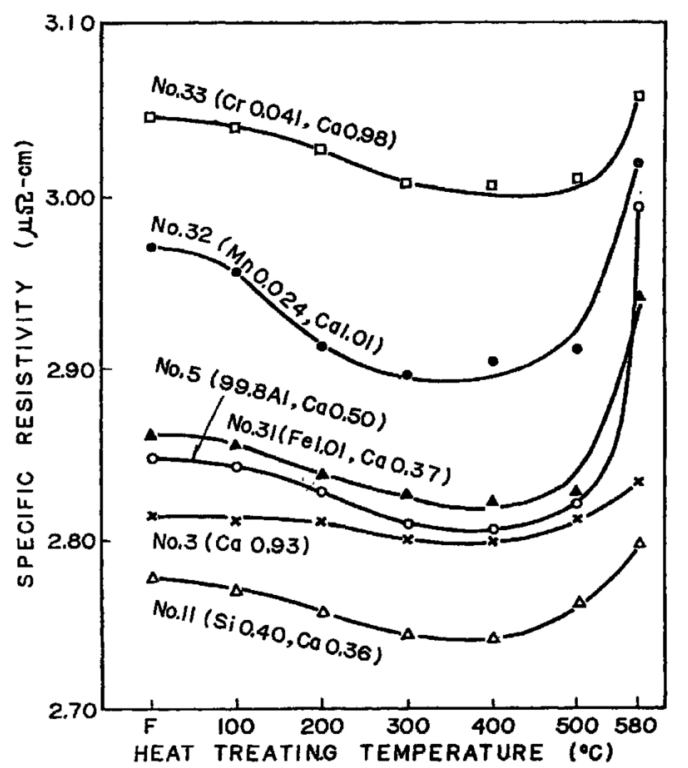

Fig. 7 Effect of heat treating to.nperature on electrical resistivity of some specimens.

is added and subjected to proper precipitation heat treatment.

All the results obtained from the above experiments seem to support the conclusions mentioned previously. However, the experiments performed will not be sufficient to prove the justification of many of the presumptions beyond all doubt. Therefore, further examination will be expected to be carried out.

\section{Properties of Al-Ca Alloys}

Work hardening occurs even in specimens of high purity Al-Ca alloys which are subjected to complete precipitation treatment. These alloys are hard immediately after working, and become soft on keeping at room tempereture. Fig. 8 shows examples of the annealing curves held at $0^{\circ} \mathrm{C}, 20^{\circ} \mathrm{C}$, and $50^{\circ} \mathrm{C}$ 
of specimens of No. 3 alloy which were heat treated incompletely and rolled $95 \%$ at $0^{\circ} \mathrm{C}$.

Specimens which were softened by keeping at room temperature ss described above, will harden again when some work is done on them. Further,

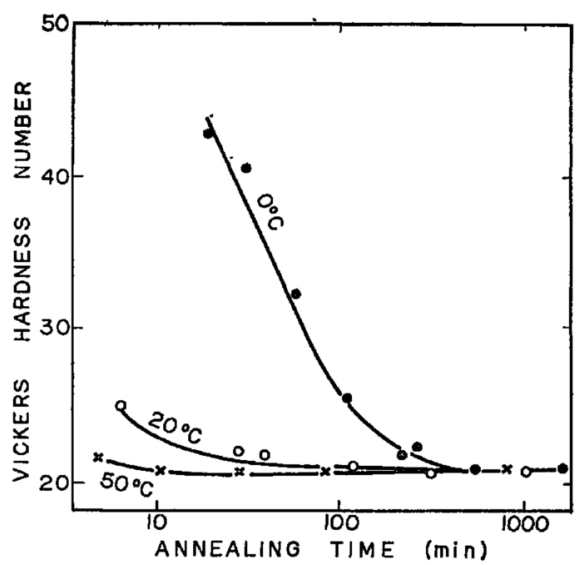

Fig. 8 Low temperature isothermal annealing curves of specimen No. 3 which was rolled $95 \%$ at $0^{\circ} \mathrm{C}$.

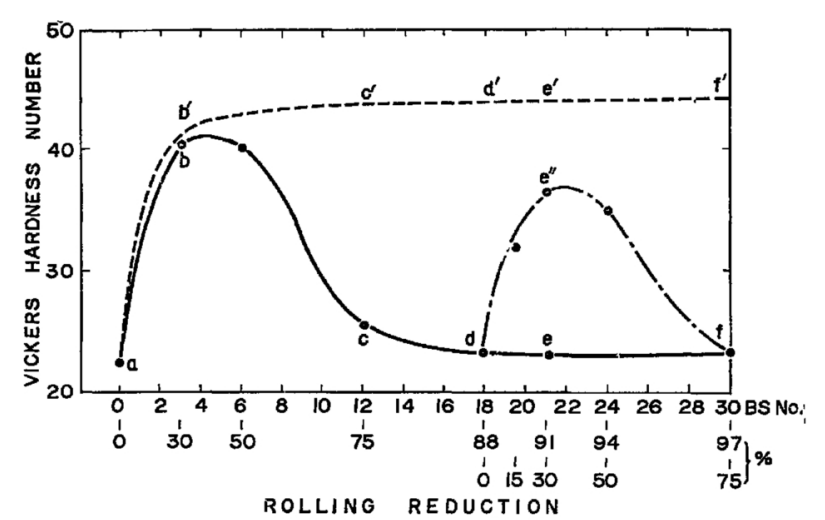

Fig. 9 Influence of reduction by rolling and the reducing schedule on hardness of specimen No. 3 .

when the degree of reworking becomes large, the specimens will sofien in the same manner as above. In such a way, it is possible to produce hard and soft states by working only. Fig. 9 shows the state of softening or hardening of the same specimen depending on the degree of working. Point a shows the hardness of $4 \mathrm{~mm}$ thick sheet which were annealed, points $b^{\prime}, c^{\prime}$ to $f^{\prime}$ show the estimated harđness of that specimen immediately after $30 \%, 75 \%$ to $97 \%$ rolling at room temperature, and $b, d$, e show the bardness after keeping $b^{\prime}, d^{\prime}, e^{\prime}$ at room temperature for 24 hours. In this way, the more the specimens are subjected to working, the lower will the recrystallization temperature become, but, for example, even if the specimens are subjected to total working of $91 \%$, a hard material $\mathrm{e}^{\prime \prime}$ will be obtained when rolling is done with intermediate pause at $\mathrm{d}^{\prime}$, resulting in the process of $\mathrm{a} \rightarrow \mathrm{d}^{\prime} \rightarrow \mathrm{d} \rightarrow \mathrm{e}^{\prime} \rightarrow \mathrm{e}^{\prime \prime}$. Complete recrystallization of the softened materials $d, e, f$ and of Fig. 8 was verified by $\mathrm{X}$-ray examination.

From their nature, Al-Ca alloys which were produced according to a proper process, besides having low recrystallization temperatures, naturally show similar properties of high purity aluminium, namely, good electrical conductivity, corrosion resistance, and softnese.

It has been known for a long time that the electrical conductivity can be raised by the addition of calcium, (19) but the effect will become greater by carrying out proper heat treatment. For instance, the specific resistance of three kinds of wires, that of $99.78 \%$ aluminium, to which $0.07 \%$ of calcium was added, and that subjected to proper heat treatment after addition of calcium were $2.77,2.76$ and 2.74 $\mu \Omega$-cm respectively.

Annealed specimens made by the same working process from aluminium of $99.78 \%$ purity and an alloy with $0.2 \%$ calcium added showed tensile strengths of $7.0 \mathrm{~kg} / \mathrm{mm}^{2}$ and $5.8 \mathrm{~kg} / \mathrm{mm}^{2}$ respectively.

Though, corrosion resistance has been known to be improved by the addition of calcium, ${ }^{(19)}$ it became clear that the characteristic could be improved further by subjecting the Al-Ca alloys to proper heat treatment.

In these cases, it is necessary to limit calcium to the least possible amount.

\section{Elements Which Aid the Effects of Calcium on Aluminium}

Even when the amounts of impurities such as magnesium, manganese and copper exceeds the allowable amounts of Table 3 , there is still the possiblility of lowering the recrystallization temperatures. Experimental results are shown in Table 5 , in which specimcns were made of $99.995 \%$ aluminium and worked according to the process described in section 3.

Table 5 Effective additions which improve the effects of calcium.

\begin{tabular}{|c|c|c|c|c|}
\hline $\begin{array}{l}\text { Specimen } \\
\text { No. }\end{array}$ & $\begin{array}{l}\text { Impurity } \\
\text { added wt \% }\end{array}$ & $\underset{\text { wt } \%}{\mathrm{Ca}}$ & $\begin{array}{l}\text { Added ele- } \\
\text { ment wt } \%\end{array}$ & $\begin{array}{c}\text { Recrystallization } \\
\text { temperature }{ }^{\circ} \mathrm{C}\end{array}$ \\
\hline $\begin{array}{l}34 \\
35\end{array}$ & $\begin{array}{l}\mathrm{Mg} 0.025 \\
\mathrm{Mg} 0.025\end{array}$ & $\overline{1.0}$ & $\begin{array}{ll}\text { Sn } & 0.2 \\
\text { Sn } & 0.2\end{array}$ & $\begin{array}{l}275 \\
\text { room temperature }\end{array}$ \\
\hline $\begin{array}{l}36 \\
37\end{array}$ & $\begin{array}{l}\mathrm{Mn} 0.04 \\
\mathrm{Mn} 0.04\end{array}$ & $\begin{array}{l}1.0 \\
1.0\end{array}$ & $\begin{array}{ll}\mathrm{Fe} & 0.5 \\
\mathrm{Ni} & 0.4\end{array}$ & $\begin{array}{r}100 \\
50\end{array}$ \\
\hline $\begin{array}{l}38 \\
39\end{array}$ & $\begin{array}{ll}\mathrm{Cu} & 0.3 \\
\mathrm{Cu} & 0.3\end{array}$ & $\begin{array}{l}1.0 \\
1.0\end{array}$ & $\mathrm{Ni} \quad \overline{0.2}$ & $\begin{array}{l}200 \\
150\end{array}$ \\
\hline $\begin{array}{l}40 \\
41 \\
42\end{array}$ & $\begin{array}{ll}\mathrm{Si} & 0.6 \\
\mathrm{Si} & 0.6 \\
\mathrm{Si} & 0.6\end{array}$ & $\begin{array}{l}0.2 \\
0.2 \\
0.2\end{array}$ & $\begin{array}{ll} & - \\
\mathrm{Be} & 0.06 \\
\mathrm{Sr} & 0.2\end{array}$ & $\begin{array}{r}300 \\
100 \\
50\end{array}$ \\
\hline $\begin{array}{l}43 \\
44 \\
45\end{array}$ & $\begin{array}{l}99.36 \% \mathrm{Al}^{*} \\
99.36 \% \mathrm{Al} \\
99.36 \% \mathrm{Al}\end{array}$ & $\begin{array}{l}1.0 \\
1.0 \\
1.0\end{array}$ & $\begin{array}{ll}\mathrm{Ni} & 0.1 \\
\mathrm{~B} & 0.2\end{array}$ & $\begin{array}{r}300 \\
75 \\
75\end{array}$ \\
\hline
\end{tabular}

* (Fe 0.40, Si 0.10, Cu 0.10, Mn 0.02, Zn 0.02, Mg tr.)

When certain elements such as tin, nickel, iron, boron, etc., are added together with calcium, large amount of harmful impurities can be changed to a harmless state very readily. For instance, tin combines with magnesium and forms $\mathrm{Mg}_{i} \mathrm{Sn}$ which hardly forms a solid solution in aluminium at low temperature, (29) and thus, even if the amount of magnesium is more than the allowable amount, it can

(29) I. Obinata and O. Murata: J. Japan Inst. Metals, 8 (1944), No. 1,3 . 
easily be changed to a barmless state. However, as tin does not have the ability of changing the impurities other than magnesium to harmless states, in the case of adding tin alone the effects of such addition will not be apparent.

It can be assumed that the action of other effective added elements will be of entirely the same mechanism. Strontium and beryllium individually will be effective in changing silicon to a harmless state and even when calcium is also present, there will be no harm on such effects. The effects of beryllium and nickel have already been found out, (15)(19) and it is a well known fact that boron changes titanium to a harmless state.

Further, it became clear that silicon also, under certain conditions, such as when the purity of aluminium is low, shows frequently the function of an effective added element. Anderson(15) also reported similar eff ect.

\section{Conclusion}

Recrystallization temperature of zone-refined superhigh purity aluminium, i. e., that of aluminium itself is extremely low, but recrystallization of commercial aluminium usually does not occur unless heated to ebout $300^{\circ} \mathrm{C}$, as very small amount of impurities is decisive in raising the recrystallization temperature.

In the past, some attempts were made to cancel the effects of impurities by deliberate addition of other elements, but sufficient results were not obtained.

In this research, the author was successful in changing the impurity elements completely to a harmless state and in lowering the recrystallization temperature of commercial aluminium to below room temperature by the addition of calcium and subjection to proper heat treatments.

Similarly, it was proved that strontium shows the same effects as those of calcium, and lowers the recrystallization temperature of $99.78 \%$ aluminium to room temperature. However, the effects of strontium are inferior to those of calcium.

The results of the author clarify the effects of other elements such as tin, iron, nickel and boron. Each. of these elements has the ability to change certain impurity elements to harmless states, which are difficult to be chenged by calcium, and so even considerable amounts of such impurities are changed very readily by the addition of the above mentioned elements together with calcium. The effects of beryllium and silicon were also confirmed.

Recently, it was reported that cobalt can lower the recrystallization temperature of high purity aluminium considerably. $(30)$
From the above results it may be concluded that the main property required for the elements to be added to aluminium of low purity and which can purify the aluminium matrix is for such elements to have the characteristic of not forming a solid solution in aluminium. And it may be necessary for such elements to react with impurities, and for the compounds formed by such reaction not to be in a solid solution in aluminium. Particularly, the compounds formed with impurities usually present in aluminium in large amounts such as silicon should not have the ability to form a solid solution.

The effects of beryllium and silicon may be of the same kind as those of calcium and strontium, and these are based on the fact that beryllium and silicon form a solid solution in aluminium at low temperature to a slight extent only. (25)

The above consideration can be applied to metals other than aluminium. For instance, the phenomenon of remarkable lowering of the recrystallization temperature of silver by the addition of small amounts of iron is known. (31)

Among the various elements to be added to aluminium, the reason for the effects of calcium, in particular, to be great is that it is chemically active, and combines well with the impurity elements resulting in the increase in its ability to change the elements of impurities to harmless states.

It may be said that the Al-Ca alloy is none other than a kind of super-purified aluminium. However, since it is considered that such aluminium contains large amout of intermetallic compouds and that a very small amount of other elements remains in a solid solution then such aluminium shows only intermediate values between high purity aluminium and commercial aluminium used, with regard to such properties as electrical conductivity, softness, and corrosion resistance, except room tempereture softening characteristic.

\section{Acknowledgements}

The author wishes to thank Professor J. Takamura, Kyoto University, for helpful discussions and to Dr. H. Tanaka for continued support and encouragement. $\mathrm{He}$ is also much indebted to Mr. M. Shibata, Mr. M. Kobayashi, Mr. K. Watanabe, Mr. Y. Suzuki, Mr. Tanaka and Mr. T. Hoshiro for their help in the experiments.

(30) K. Shimizu and Y. Nakatani : Lectrere at the Spring Meeting of the Inst. of Light Metals (Japan) (1960); M. Nakamura, S. Matsuo and M. Yanagisawa: Reports of the Goverment Ind. Inst. Nagoya, 5 (1956), 114.

(31) Widmann: Z. Physik. 45 (1927), 200. 